\title{
Potential Vectors of Dirofilaria immitis (Leidy, 1856) in Itacoatiara, Oceanic Region of Niterói Municipality, State of Rio de Janeiro, Brazil
}

\author{
Norma Labarthe/ ${ }^{+}$, Maria Lúcia Serrão*, Yuri Fontenele Melo, Sebastião José \\ de Oliveira**, Ricardo Lourenço-de-Oliveira*
}

Faculdade de Veterinária, Centro de Ciências Médicas, Universidade Federal Fluminense, Rua Vital Brazil Filho 64, 24230-340 Niterói, RJ, Brasil *Laboratório de Transmissores de Hematozoários **Coleção Entomológica, Departamento de Entomologia, Instituto Oswaldo Cruz, Av. Brasil 4365, 21045-900 Rio de Janeiro, RJ, Brasil

Dirofilaria immitis is a widespread mosquito-borne parasite that causes dirofilariasis, a commonly diagnosed disease of dogs that is rarely reported in cats and humans. A mosquito survey was conducted in Itacoatiara in the State of Rio de Janeiro, from March 1995 to February 1996, using canine, feline and human baits. A total of 3,667 mosquitoes were dissected for $\mathrm{D}$. immitis larvae, representing 19 species and 10 genera. From those, Ae. scapularis, Ae taeniorhynchus, Cx. quinquefasciatus, Cx. declarator, $\mathrm{Cx}$. saltanensis and $\mathrm{Wy}$. bourrouli were found infected with $\mathrm{D}$. immitis parasites, and among those, only the first three harbored infective larvae. The majority of larvae were found in the Malpighian tubules (889/936), and larval melanization was observed in the two Aedes species. In descending order, the best vectors were Ae. scapularis, Ae. taeniorhynchus, and $\mathrm{Cx}$. quinquefasciatus which alternate seasonally in importance. Cx. quinquefasciatus is suggested to be a vector to cats. The potential transmission of $\mathrm{D}$. immitis parasites by these three vectors to man is discussed.

Key words: Dirofilaria immitis - mosquitoes - heartworm - potential vector

Dirofilaria immitis (Leidy 1856) is a widespread mosquito-borne nematode parasite of dogs. While canine heartworm is enzootic in many areas (Guerrero et al. 1992a), feline dirofilariasis is much less common. Feline heartworm infections parallels that of dogs in a defined area. While feline dirofilariasis is at a lower infection rate than canine dirofilariasis (Dillon 1988, Elkins \& Kadel 1988), it is thought to be increasing in prevalence and distribution (Guerrero et al. 1992b). Heartworm is also a zoonosis (OMS 1979).

Heartworm is common in dogs in Rio de Janeiro, Brazil (21.3\%). In the coastal region of the county of Niterói an even higher prevalence is observed $(37.5 \%)$, and microfilaremic dogs, the source of mosquito infections, account for $25 \%$ of the local population (Labarthe et al. 1997a).

Dogs may have high levels of microfilaremia $\left(10^{3}\right.$ to $10^{5} / \mathrm{ml}$ ) (Lok 1988). Mosquitoes bloodfeeding on dogs with even moderate numbers of microfilariae frequently die (Sauerman 1980). Mosquitoes need to survive $D$. immitis infection in order to support the extrinsic cycle of the nema-

${ }^{+}$Corresponding author. Fax: + 55-21-295.2052

Received 6 January 1998

Accepted 17 April 1998 tode through development of infective third stage larvae $\left(\mathrm{L}_{3}\right)$. Vector survival seems to rely on biochemical reactions which limit the nematode burden in the mosquito (Christensen 1977, 1978, 1981). Intrinsic barriers to D. immitis development in mosquitoes include: larval damage due to the cibarial armature (Coluzzi \& Trabucchi 1968) or to the presence of oxyhaemoglobin crystals formed by bloodmeal coagulation in the midgut (Nayar \& Sauerman 1975, Lowrie 1991); trapping of larvae in the coagulated bloodmeal in the mosquito's midgut (Kartman 1953); lysis of larval cuticle by host cells (Talluri \& Cancrini 1994) and other immune responses, i.e., encapsulation and/or melanization of the parasite in the mosquito Malpighian tubules (Lindemann 1977, Christensen 1981, Christensen et al. 1989). Among extrinsic factors, temperature is the most important and has been shown to regulate the duration of parasite development in the mosquito (Kutz \& Dobson 1974, Christensen \& Hollander 1978).

Laboratory and field data show that many mosquito species, from different geographic areas worldwide, are susceptible and yield infective larvae under field or laboratory conditions. Although more than 60 mosquito species have been identified as potential vectors of $D$. immitis worldwide (Ludlam et al. 1970), their vectorial capacity varies (Sauerman 1980). In the Americas, mosquito 
species belonging to the subgenus Ochlerotatus of Aedes are considered the best vectors of heartworm (Yen 1938, Kershaw et al. 1953, Ludlam et al. 1970, Christensen 1977, Arnott \& Edman 1978, Buxton \& Mullen 1980, Walters \& Lavoipierre 1982, Sauerman \& Nayar 1983, Ernst \& Slocombe 1984, Hribar \& Gerhardt 1985, Roberts et al. 1985, Johnson \& Harrell 1986, Parker 1986, 1993, Scoles et al. 1993, Loftin et al. 1995). In Brazil, there are two reports: one under experimental conditions with Ae. fluviatilis (Lutz) that suggested that although infective larvae have been found in some individuals, this species is not likely to be an efficient vector in nature (Kasai \& Williams 1986) and another in which Ae. taeniorhynchus (Wiedemann) and Ae. scapularis (Rondani) were shown to be suitable natural potential vectors of heartworms in Rio de Janeiro (Lourenço-de-Oliveira \& Deane 1995).

In nature, the complete life cycle of the mosquito must be considered before concluding either that a given species or strain is a probable vector of $D$. immitis. The present study examines infection rates of mosquito species with $D$. immitis at Niterói in relation to their biology (feeding behavior and seasonal biting frequency).

\section{MATERIALS AND METHODS}

Mosquitoes were collected in Itacoatiara, State of Rio de Janeiro, where the average prevalence of canine microfilaremic heartworm is $31.7 \%$ (unpublished data). Data on the collection sites and methods are available in Labarthe et al. (1998). Briefly, mosquitoes were captured four days each month using a dog, a cat and two human volunteers as baits, from March 1995 until February 1996.

Mosquitoes were kept in cylindrical cages of $8.5 \mathrm{~cm}$ diameter at $28^{\circ} \mathrm{C}, 80 \% \mathrm{RH}$ and provided with a $10 \%$ glucose solution. Dissection of live females was initiated immediately after collections, and all mosquitoes were dissected within five days of collection. After chloroform anesthesia, each mosquito was identified using taxonomic keys of Lane (1953) and Consoli and Lourenço-de-Oliveira (1994). Subsequently, the head was placed in a small saline droplet on a microscope slide, and the alimentary tract and Malpighian tubules were drawn from the body into another saline droplet by gently pulling the terminal segments backwards with hypodermic needles. The thorax was teased apart in a third droplet of saline. All preparations were examined for the presence of worms under microscopic magnification after placement of a coverslip.

Larvae found in the mosquitoes were identified as D. immitis based on: morphological char- acteristics previously described (Taylor 1960) and those observed in experimental infections (Macêdo et al. 1998); the Malpighian tubule developmental site of worms, known only among species of the genus Dirofilaria of Onchocercidae (Symes 1960, Walters \& Lavoipierre 1982, Sauerman \& Nayar 1983); the only Dirofilaria species known from the lowlands of Rio de Janeiro is D. immitis (Lourençode-Oliveira \& Deane 1995); and the mosquito collecting site is an active $D$. immitis transmission focus (Labarthe et al. 1997a).

The infection rate was determined as the percentage of numbers of a species infected with any stage larvae (Chandra et al. 1996). The transmission capacity of each species was determined by the annual transmission potential (ATP) that corresponds to the sum of the monthly transmission potentials (MTP) (WHO 1987), where:

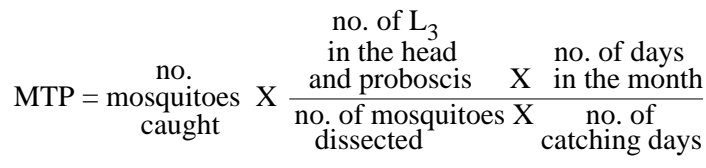

The frequencies of infected and infective mosquitoes (with $\mathrm{L}_{3}$ in head and proboscis) were analyzed by chi-square or when values were less than 5 , Fisher's exact test was used (Mood \& Graybill 1963, Rodrigues 1993).

\section{RESULTS}

A total of 3,667 mosquitoes belonging to 19 species and 10 genera was captured and dissected. From those, six species were found naturally infected with various larval stages. Only $A e$. taeniorhynchus, Cx. quinquefasciatus and Ae. scapularis harbored infective larvae in the head and proboscis, and so were rated as infective (Table I). Traditional statistical analysis crossing species versus infective and infected mosquitoes showed little or no relevance to the objective of the present study as chi-squares and Fisher tests became less statistically significant as relevant species were segregated and crossed among each other. When the number of uninfected Ae. taeniorhynchus, $C x$. quinquefasciatus, Ae. scapularis and Cx. declarator captured were analyzed versus their infected members, Ae. taeniorhynchus was the most infected, followed by Ae. scapularis, Cx. quinquefasciatus and Cx. declarator (chi-square 19.1, $\mathrm{p}<0.01)$. When infectivity was analyzed, Fisher test showed $\mathrm{p}>0.07$ for all combinations among the three species found infective.

A total of 936 larvae was found among the dissected mosquitoes. The majority of larvae (889/ 936) was found in the Malpighian tubules (Fig. a) and half of the infective mosquitoes (4/8) still har- 
bored either L2 or L3 larvae in the tubules. Twenty eight infective larvae were found in the head and proboscis of mosquitoes: eighteen were found in Ae. scapularis (Fig. b) in January 1996; four in April and three in July 1995 in Ae. taeniorhynchus (Fig. c); and two in August and one in November 1995 in Cx. quinquefasciatus. Melanization of larvae was observed only in the two Aedes species. In Ae. taeniorhynchus and Ae. scapularis, 9.5\% and $16.7 \%$ of the harbored larvae were melanized, respectively (Table I). All Ae. taeniorhynchus with some melanized larvae had at least 45 larvae, except for one with 55 larvae in the cells of the Malpighian tubules, none of which were melanized. Among Ae. scapularis, melanization was observed even when the mosquito had as few as eight larvae. However, melanization of larvae was not observed in six Ae. scapularis harboring 9-20 larvae.

When the ATP was considered, the best vector in the surveyed area was Ae. scapularis, followed by Ae. taeniorhynchus and $C x$. quinquefasciatus (Table I).

Infected mosquitoes were found in every month of the year, but February, while infective mosquitoes were found sparsely throughout the year (Table II).

\section{DISCUSSION}

To vector $D$. immitis, mosquitoes must live long enough to allow complete filarial development. Multivoltine species would probably make better vectors than univoltine species, and a specie's flight range and host seeking preference can influence the importance of a species as a vector (Ludlam et al. 1970, Otto \& Jachowski 1980). In the present survey, Ae. taeniorhynchus, Ae. scapularis and $C x$. quinquefasciatus were found to fulfill these prerequisites and to be natural vectors of $D$. immitis in Itacoatiara. Ae. taeniorhynchus and $C x$. quinquefasciatus have been known as natural vectors of D. immitis in other areas (Villavaso \& Steelman 1970, Sauerman \& Nayar 1983, Russell 1985, Parker 1986, 1993). In Rio de Janeiro, both Ae. taeniorhynchus and Ae. scapularis have already been found naturally infected with presumed $D$. immitis larvae and considered to be potential vectors of the parasite (Lourenço-de-Oliveira \& Deane 1995). In the surveyed area the annual transmission potential (ATP) for Ae. scapularis was approximately three times that of Ae. taeniorhynchus and six times more than that of $C x$. quinquefasciatus. The differences in ATP values is related to variations in mosquito population density, biting frequency and distribution throughout the year (Labarthe et al. 1998), showing that Ae. scapularis is the most important vector in Itacoatiara, followed closely by $A e$.

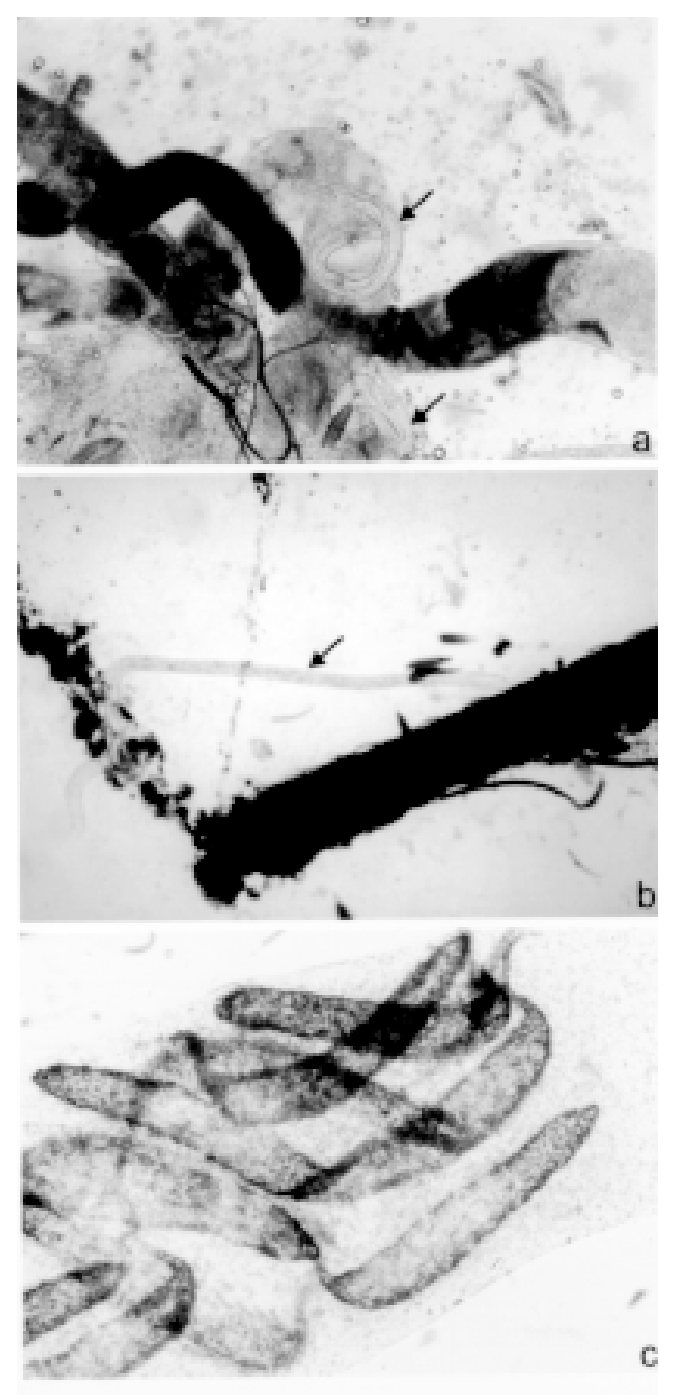

Dirofilaria immitis larvae in different developing stages found in naturally infected mosquitoes from Itacoatiara, State of Rio de Janeiro. a: larvae developing in the Malpighian tubules of Aedes taeniorhynchus (negative $125 \mathrm{x}$ ); b: infective larva recently emerged from the proboscis of Ae. scapularis (negative $100 \mathrm{x})$; c: melanized sausage stage larvae in the Malpighian tubules of Ae. taeniorhynchus (negative 400x).

taeniorhynchus. Cx. quinquefasciatus is a secondary vector. In localities in the State of Rio de Janeiro (FEEMA 1983) where the hemisynanthropic primary vectors are abundant, canine heartworm frequency is high while where the endophilic secondary vector predominates, canine heartworm frequency is low (Labarthe et al. 1992, Souza 1992).

Cx. declarator, Cx. saltanensis and Wy. bourrouli did not harbor infective larvae and have never been described as potential vectors of $D$. immitis. Therefore, their infections are thought to be a dead end and if so, have no epidemiological 
TABLE I

Infection rate, infective mosquitoes, larvae melanization and annual transmission potential (ATP) of mosquitoes infected with Dirofilaria immitis, captured in Itacoatiara, State of Rio de Janeiro, Brazil with human, canine and feline baits

\begin{tabular}{lcccr}
\hline Species & Infection rate ${ }^{a}$ & $\begin{array}{c}\text { Infective } \\
\text { mosquitoes } b\end{array}$ & Larvae melanization ${ }^{c}$ & ATP $^{d}$ \\
\hline Aedes taeniorhynchus & $31 / 1037(3 \%)$ & $2 / 31$ & $60 / 630(9.5 \%)$ & 57.2 \\
Ae. scapularis & $13 / 715(1.8 \%)$ & $3 / 13$ & $44 / 264(16.7 \%)$ & 147.6 \\
Culex quinquefasciatus & $8 / 865(0.9 \%)$ & $3 / 8$ & $0 / 28$ & 23.4 \\
Cx. declarator & $2 / 644(0.3 \%)$ & 0 & $0 / 12$ & 0 \\
Wyeomyia bourrouli & $1 / 43(2.3 \%)$ & 0 & $0 / 1$ & 0 \\
Cx. saltanensis & $1 / 17(5.9 \%)$ & 0 & $0 / 1$ & 0 \\
Other species ${ }^{e}$ & $0 / 346$ & 0 & 0 & 0 \\
\hline Total & $56 / 3667$ & $8 / 52$ & $104 / 936$ & 228.2 \\
\hline
\end{tabular}

$a$ : no. of female mosquitoes found harboring any larval stage/total no. of dissected mosquitoes; $b$ : no. of mosquitoes found with L3 in head and/or proboscis/no. of infected mosquitoes; $c$ : total no. of melanized larvae found/total no. of larvae; $d$ : the sum of the monthly transmission potentials (WHO 1987); $e$ : other captured species in Labarthe et al. (1998).

importance in heartworm transmission in the surveyed area.

Melanization of larvae seems to be an important survival reaction of Aedes mosquitoes to $D$. immitis infection (Lindemann 1977, Christensen 1977, 1978, 1981, Christensen et al. 1989). Melanized larvae were seen in all heavily infected $A e$. taeniorhynchus mosquitoes but one, which had all 55 larvae in the cells of the Malpighian tubules, suggesting that the infection was too recent for melanization to have taken place. Ae. scapularis mosquitoes melanized a larger proportion of larvae than Ae. taeniorhynchus, and melanization did not seem to be related to the number of larvae. Since Cx. quinquefasciatus mosquitoes were never observed with melanized larvae but always had smaller numbers of larvae than Ae. scapularis and Ae. taeniorhynchus, it seems that they control larval burden by other mechanisms, such as by reducing the number of larvae by the cibarial armature (Coluzzi \& Trabucchi 1968).

Transmission at Itacoatiara can potentially occur throughout the year, since infected and infective mosquitoes were found, respectively, in 11 and 5 months of the year. Environmental temperature directly influences the rate of larval development in the mosquito (Kutz \& Dobson 1974, Christensen \& Hollander 1978) so, transmission potential can change seasonally with temperature. Different species of mosquitoes were infective during different months: Ae. taeniorhynchus in autumn and early winter, Cx. quinquefasciatus in winter and spring and Ae. scapularis in the summer. These data strongly suggest that in the surveyed area, monthly heartworm chemoprophylaxis should be given to dogs year-round, in contrast with north temperate latitudes, where chemoprophylaxis is recom- mended only during some months, depending mainly on the recorded temperatures of each region (Knight \& Lok 1995, Slocombe et al. 1995).

Cats, in spite of being susceptible to D. immitis (McCall et al. 1992), are rarely found naturally infected. For instance, in urbanizing sections of Rio de Janeiro, where the canine heartworm prevalence is high (30.9\%) (Labarthe et al. 1997a), feline heartworm prevalence is $1.6 \%$ (Labarthe et al. 1997b). This expressive difference in prevalence may be explained by the fact that the primary vectors of the parasite, Ae. scapularis and Ae.taeniorhynchus, are hemisynanthropic mosquito species which seek cats almost accidentally (Labarthe et al. 1998). Cx. quinquefasciatus, herein considered a secondary vector, is the only vector species commonly associated with cats (Genchi et al. 1992, Labarthe et al. 1998). That is, the potential mosquito vector for cats is a modest $D$. immitis vector in Rio de Janeiro. Furthermore, both cats and $C x$. quinquefasciatus show marked nocturnal behavior: free cats are active at the time when the vectors are seeking blood meals, making it more difficult for mosquitoes to feed on them. Although somehow protected from mosquitoes, 33 to $36 \%$ of heartworm positive cats are indoors (Atkins 1997). Cx. quinquefasciatus is an endophilic species (Deane 1951, Rachou 1956), therefore, in places where their density is high, once an infective mosquito comes in the house, it can feed on cat and infect it.

Since D. immitis is infective to man (OMS 1979), is frequently diagnosed among Brazilians (Campos et al. 1997), the three natural vectors (Ae. scapularis, Ae. taeniorhynchus and $C x$. quinquefasciatus) have been shown to seek humans in the studied heartworm focus (Labarthe et al. 1998), human cases of dirofilariasis may be expected in 
TABLE II

Monthly frequency of mosquitoes infected with Dirofilaria immitis captured in Itacoatiara, State of Rio de Janeiro, Brazil, with human, canine and feline baits and number of live larvae and of infective mosquitoes

\begin{tabular}{|c|c|c|c|c|c|c|c|c|c|c|c|c|c|}
\hline \multirow[t]{3}{*}{ Species } & \multirow{2}{*}{\multicolumn{10}{|c|}{ Frequency $^{a}$}} & \multirow{2}{*}{\multicolumn{2}{|c|}{1996}} & \multirow[b]{3}{*}{ Total } \\
\hline & & & & & & & & & & & & & \\
\hline & Mar & Apr & May & Jun & Jul & Aug & Sep & Oct & Nov & Dec & Jan & Feb & \\
\hline Aedes taeniorhynchus & $1 / 50$ & $4 / 393^{b}$ & $7 / 162$ & $14 / 218$ & $2 / 97^{b}$ & $1 / 32$ & - & $0 / 44$ & $2 / 25$ & $0 / 14$ & $0 / 2$ & - & $31 / 1037^{d}$ \\
\hline No. of live larvae & 2 & 82 & 144 & 234 & 9 & 55 & - & 0 & 44 & 0 & 0 & - & 570 \\
\hline Ae. scapularis & $0 / 8$ & $0 / 35$ & $2 / 38$ & $0 / 37$ & $0 / 55$ & $0 / 83$ & $0 / 2$ & $0 / 84$ & $4 / 169$ & $3 / 56$ & $4 / 141^{c}$ & $0 / 7$ & $13 / 715^{c}$ \\
\hline No. of live larvae & 0 & 0 & 10 & 0 & 0 & 0 & 0 & 0 & 96 & 24 & 90 & 0 & 220 \\
\hline Culex quinquefasciatus & $0 / 73$ & $0 / 77$ & $0 / 34$ & $1 / 44$ & $0 / 22$ & $4 / 94^{d}$ & $1 / 151$ & $1 / 94$ & $1 / 26^{b}$ & $0 / 61$ & $0 / 82$ & $0 / 107$ & $8 / 865^{c}$ \\
\hline No. of live larvae & 0 & 0 & 0 & 2 & 0 & 21 & 2 & 2 & 1 & 0 & 0 & 0 & 28 \\
\hline Cx. declarator & - & - & - & $0 / 1$ & $0 / 34$ & $0 / 40$ & $0 / 5$ & $0 / 6$ & $1 / 161$ & $1 / 256$ & $0 / 125$ & $0 / 16$ & $2 / 644$ \\
\hline No. of live larvae & - & - & - & 0 & 0 & 0 & 0 & 0 & 11 & 1 & 0 & 0 & 12 \\
\hline Wyeomyia bourrouli & $0 / 5$ & $1 / 9$ & $0 / 10$ & $0 / 1$ & $0 / 2$ & $0 / 1$ & $0 / 1$ & - & $0 / 3$ & $0 / 6$ & $0 / 4$ & $0 / 1$ & $1 / 43$ \\
\hline No. of live larvae & 0 & 1 & 0 & 0 & 0 & 0 & 0 & - & 0 & 0 & 0 & 0 & 1 \\
\hline Cx. saltanensis & - & $1 / 1$ & $0 / 3$ & $0 / 2$ & $0 / 5$ & $0 / 1$ & - & - & $0 / 1$ & - & $0 / 4$ & - & $1 / 17$ \\
\hline No. of live larvae & - & 1 & 0 & 0 & 0 & 0 & - & - & 0 & - & 0 & - & 1 \\
\hline Total & $1 / 136$ & $6 / 515^{b}$ & $9 / 247$ & $15 / 303$ & $2 / 215^{b}$ & $5 / 251^{d}$ & $1 / 159$ & $1 / 228$ & $8 / 385^{b}$ & $4 / 393$ & $4 / 358^{c}$ & $0 / 131$ & $56 / 3321$ \\
\hline No. of live larvae & 2 & 84 & 154 & 236 & 9 & 76 & 2 & 2 & 152 & 25 & 90 & 0 & 832 \\
\hline
\end{tabular}

$a$ : infected mosquitoes/total dissected; $b$ : one mosquito with infective larvae in head and/or mouthparts; $c$ : three mosquitoes with infective larvae in head and/or mouthparts; $d$ : two mosquitoes with infective larvae in head and/or mouthparts. 
the study area. Also, since both the canine and culicidae fauna are similar along the lowland areas in the State of Rio de Janeiro (Labarthe et al. 1997a, Lourenço-de-Oliveira 1985a,b), health professionals should more seriously consider dirofilariasis among the many possible causes of solitary lesions of the human lung (Levinson et al. 1979, Campos et al. 1997).

\section{ACKNOWLEDGMENTS}

To Carlos Alberto Coimbra and Antônio Bernardo da Costa for discussing data. To LP Lounibos for the critical reading of the manuscript. To Genilton Vieira and Heloisa MN Dinis for assistence with images.

\section{REFERENCES}

Arnott JJ, Edman JD 1978. Mosquito vectors of dog heartworm, Dirofilaria immitis, in western Massachussetts. Mosq News 38: 222-229.

Atkins C 1997. Feline heartworm disease. Feline Practice 25: 12-21.

Buxton JA, Mullen GR 1980. Field isolations of Dirofilaria immitis from mosquitoes in Alabama. $J$ Parasitol 66: 140-144.

Campos JRM, Barbas CSV, Filomeno LTB, Fernandez A, Minamoto H, Barbas Filho JV, Jatene FB 1997. Human pulmonary dirofilariasis. Analysis of 24 cases from São Paulo, Brazil. Chest 112: 729-733.

Chandra G, Seal B, Hati AK 1996. Age composition of the filarial vector Culex quinquefasciatus (Diptera: Culicidae) in Calcutta, India. Bull Entomol Res 86: 223-226.

Christensen BM 1977. Laboratory studies on the development and transmission of Dirofilaria immitis by Aedes trivittatus. Mosq News 37: 367-372.

Christensen BM 1978. Dirofilaria immitis: Effect on the longevity of Aedes trivittatus. Exp Parasitol 44:116123.

Christensen BM 1981. Observations on the immune response of Aedes trivittatus against Dirofilaria immitis. Trans $R$ Soc Trop Med Hyg 75: 439-443.

Christensen BM, Hollander AL 1978. Effect of temperature on vector-parasite relationships of Aedes trivittatus and Dirofilaria immitis. Proc Helminthol Soc Washington 45: 115-119.

Christensen BM, Huff BM, Miranpuri GS, Harris KL, Christensen LA 1989. Hemocyte population changes during the immune response of Aedes aegypti to inoculated microfilariae of Dirofilaria immitis. $J$ Parasitol 75: 119-123.

Coluzzi M, Trabucchi R 1968. Importanza de l'armatura buccofaringeana in Anopheles e Culex in relazione alle infezioni con Dirofilaria. Parassitologia 10: 4759.

Consoli RAGB, Lourenço-de-Oliveira R 1994. Principais Mosquitos de Importância Sanitária no Brasil, Fiocruz, Rio de Janeiro, 228 pp.

Deane LM 1951. Observações sobre alguns hábitos dos adultos de Culex fatigans, o principal transmissor da filariose em Belém do Pará. Rev SESP 4: 423-461.

Dillon AR 1988. Feline Heartworm disease, p. 205-215.
In PFL Boreham \& RB Atwell (eds), Dirofilariasis, CRC Press, Boca Raton, FL.

Elkins AD, Kadel W 1988. Feline Heartworm disease and its incidence in Western Kentucky. Comp Cont Ed 10: 585-589.

Ernst J, Slocombe JOD 1984. Mosquito vectors of Dirofilaria immitis in southwestern Ontario. Can J Zool 62: 212-216.

FEEMA - Fundação Estadual de Engenharia do Meio Ambiente 1983. Comunicações de incidência mensal no Município do Rio de Janeiro em 1983.

Genchi C, Di Sacco B, Cancrini G 1992. Epizootiology of canine and feline heartworm infection in northern Italy: Possible mosquito vectors, p. 39-46. In Proceedings of the Heartworm Symposium, Austin, Texas.

Guerrero J, Ducos de la Hite J, Genchi C, Rojo F, GomezBautista M, Varela MC, Labarthe N, Bordin E, Gonzalez G, Mancebo O, Patino F, Uribe LF, Samano R 1992a. Update on the distribution of Dirofilaria immitis in dogs from southern Europe and Latin America, p. 31-37. In Proceedings of the Heartworm Symposium, Austin, Texas.

Guerrero J, McCall JW, Dzimianski MT, McTier TL, Holmes RA, Newcomb KM 1992b. Prevalence of Dirofilaria immitis infection in cats from the southeastern United States, p. 91-95. In Proceedings of the Heartworm Symposium, Austin, Texas.

Hribar LJ, Gerhardt RR 1985. Wild-caught Aedes trivittatus naturally infected with filarial worms in Knox County, Tennessee. J Am Mosq Control Assoc 1: $250-251$.

Johnson WE, Harrell 1986. Further study on the potential vectors of Dirofilaria immitis in Macon County, Alabama. J Parasitol 72: 955-956.

Kartman L 1953. Factors influencing infection of the mosquito with Dirofilaria immitis (Leidy,1856). Exp Parasitol 2: 27-28.

Kasai N, Williams P 1986. Infecção experimental de Aedes fluviatilis (Lutz, 1904) por Dirofilaria immitis (Leidy, 1856). Rev Brasil Biol 46: 277-283.

Kershaw WE, Lavoipierre MMJ, Chalmers TA 1953. Studies on the intake of microfilariae by their insect vectors, their survival, and their effect on the survival of their vectors. Ann Trop Med Parasitol 47: 207-224.

Knight DH, Lok JB 1995. Seasonal timing of heartworm chemoprophylaxis in the United States, p. 37-42. In Proceedings of the Heartworm Symposium, Auburn, Alabama.

Kutz FW, Dobson RC 1974. Effects of temperature on the development of Dirofilaria immitis (Leidy) in Anopheles quadrimaculatus Say and on vector mortality resulting from this development. Ann Entomol Soc Am 67: 325-331.

Labarthe N, Almosny N, Guerrero J, Duque-Araujo AM 1997a. Description of the occurrence of dirofilariasis in the State of Rio de Janeiro, Brazil. Mem Inst Oswaldo Cruz 92: 47-51.

Labarthe N, Ferreira AMR, Guerrero J, Newcomb K, Paes-de-Almeida E 1997b. Survey of Dirofilaria immitis (Leidy, 1856) in random source cats in met- 
ropolitan Rio de Janeiro, Brazil, with descriptions of lesions. Vet Parasitol 71: 301-306.

Labarthe N, Serrão ML, Melo YF, Oliveira SJ, Lourençode-Oliveira R 1998. Mosquito frequency and feeding habits in an enzootic canine dirofilariasis area in Niterói, State of Rio de Janeiro, Brazil. Mem Inst Oswaldo Cruz 93: 145-154.

Labarthe NV, Almosny NR, Soares AM, Souza-Silva LC 1992. Update on the distribution of Dirofilaria immitis in the State of Rio de Janeiro, Brazil., p. 291293. Proc XVII WSAVA Cong, Rome, Italy.

Lane J 1953. Neotropical Culicidae, 2 vol., Universidade de São Paulo, São Paulo, 1112 pp.

Levinson ED, Ziter FMH, Westcott JL 1979. Pulmonary lesions due to Dirofilaria immitis (Dog Heartworm). Radiology 131: 305-307.

Lindemann BA 1977. Dirofilaria immitis encapsulation in Aedes aegypti. Mosq News 37: 293-295.

Loftin Km, Byford RL, Loftin MJ, Craig ME 1995. Potential mosquito vectors of Dirofilaria immitis in Bernalillo County, New Mexico. J Am Mosq Assoc 11: 90-93.

Lok JB 1988. Dirofilaria sp.: taxonomy and distribution, p. 3-11. In PFL Boreham, RB Atwell (eds), Dirofilariasis, CRC Press, Boca Raton, FL.

Lourenço-de-Oliveira R, da-Silva TF 1985a. Alguns aspectos da ecologia dos mosquitos (Diptera: Culicidae) de uma área de planície (Granjas Calábria), em Jacarepaguá, Rio de Janeiro. III. Preferência horária das fêmeas para o hemofagismo. Mem Inst Oswaldo Cruz 80: 195-201.

Lourenço-de-Oliveira R, Deane L 1995. Presumed Dirofilaria immitis infections in wild-caught Aedes taeniorhynchus and Aedes scapularis in Rio de Janeiro, Brazil. Mem Inst Oswaldo Cruz 90: 387388.

Lourenço-de-Oliveira R, da-Silva TF, Heyden R 1985b. Alguns aspectos da ecologia dos mosquitos (Diptera: Culicidae) de uma área de planície (Granjas Calábria), em Jacarepaguá, Rio de Janeiro. II. Freqüência mensal e no ciclo lunar. Mem Inst Oswaldo Cruz 80: 123-133.

Lowrie RC Jr. 1991. Poor vector efficiency of Culex quinquefasciatus following infection with Dirofilaria immitis. J Am Mosq Assoc 7: 30-37.

Ludlam KW, Jachowski LA, Otto GF 1970. Potential vectors of Dirofilaria immitis. JAVMA 157: 1354-1359.

Macêdo FC, Labarthe N, Lourenço-de-Oliveira R 1998. Susceptibility of Ae. scapularis (Rondani, 1848) to Dirofilaria immitis (Leidy, 1856), an emerging zoonosis. Mem Inst Oswaldo Cruz, 93: 435-437.

McCall JW, Dzimianski MT, McTier TL, Jernigan AD, Jung JJ, Mansour AE, Supakorndej P, Plue RE, Clark JN, Wallace DH, Lewis RE 1992. Biology of experimental heartworm infections in cats, p. 71-79. In Proceedings of the Heartworm Symposium, Austin, Texas.

Mood AM, Graybill FA 1963. Introduction to the Theory of Statistics, 2nd ed., McGraw-Hill, New York, 443 pp.

Nayar JK, Sauerman DM 1975. Physiological basis of host susceptibility of Florida mosquitoes to Dirofi- laria immitis. J Insect Physiol 21: 1965-1975.

OMS - Organización Mundial de la Salud 1979. Zoonosis Parasitarias. Informe Técnico 637: 105-106.

Otto GF, Jachowski Jr LA 1980. Mosquitoes and canine heartworm disease, p. 17-32. In Proceedings of the Heartworm Symposium, Dallas, Texas.

Parker BM 1986. Presumed Dirofilaria immitis infections from field-collected mosquitoes in North Carolina. J Am Mosq Control Assoc 2: 231-233.

Parker BM 1993. Variation in mosquito (Diptera: Culicidae) relative abundance and Dirofilaria immitis (Nematoda: Filarioidea) vector potential in coastal North Carolina. J Med Entomol 30: 436-442.

Rachou RG 1956. Transmissores da filariose bancroftiana no Brasil. Rev Bras Malariol Doen Trop 8: 267-279.

Roberts E, April M, Trpis M 1985. Laboratory transmission of dog heartworm (Dirofilaria immitis) by three species of mosquitoes (Diptera: culicidae) from Eastern Maryland, USA. J Med Entoml 22: 415-420.

Rodrigues PC 1993. Bioestatística, 2nd ed., EDUFF, Niterói, RJ, 268 pp.

Russell RC 1985. Report of a field study on mosquito (Diptera: Culicidae) vectors of dog heartworm, Dirofilaria immitis Leidy (Spirurida: Onchocercidae) near Sydney, N.S.W., and the implications for veterinary and public health concern. Aust J Zool 33: 461-472.

Sauerman DM 1980. Mechanisms in Mosquitoes Responsible for Variation in Susceptibility to Infection by Dirofilaria immitis (Leidy, 1856), Etiologic Agent of Canine Heartworm Disease, PhD Thesis, University of Florida, Vero Beach, FL, 170 pp.

Sauerman, DM, Nayar JK 1983. A survey for natural potential vectors of Dirofilaria immitis in Vero Beach, FL. Mosq News 43: 222-225.

Scoles GA, Dickson SL, Blackmore MS 1993. Assessment of Ae. sierrensis as a vector of canine heartworm in Utah using a new technique for determining the infectivity rate. J Am Mosq Control Assoc 9: 88-90.

Slocombe JO, Srivastava B, Surgeoner GA 1995. The transmission period for heartworm in Canada, $\mathrm{p}$. 43-48. In Proceedings of the Heartworm Symposium, Auburn, Alabama.

Souza SSHVC 1992. Diagnóstico da Dirofilariose Através da Detecção de Antígenos Circulantes em Cães no Estado do Rio de Janeiro, MSc Thesis, Faculdade de Veterinária, Universidade Federal Rural do Rio de Janeiro, Rio de Janeiro, 87 pp.

Symes CB 1960. A note on Dirofilaria immitis and its vectors in Fiji. J Helmintol 34: 39-42.

Talluri V, Cancrini G 1994. An ultrastructural study on the early cellular response to Dirofilaria immitis (Nematoda) in the Malpighian tubules of Aedes aegypti (refractory strains). Parasite 1: 343-348.

Taylor AE 1960. The development of Dirofilaria immitis in the mosquito Aedes aegypti. J Helminth 34: 27-38.

Villavaso EJ, Steelman CD 1970. Laboratory and field studies of the southern house mosquito, Culex pipiens quinquefasciatus Say, and Dirofilaria immitis (Leidy), in Louisiana. J Med Entomol 7: 471-476. 
Walters LL, Lavoipierre MMJ 1982. Aedes vexans and Aedes sierrensis (Diptera: Culicidae): potential vectors of Dirofilaria immitis in Tehama County, Northern California, USA. J Med Entomol 19:15-23.

WHO - World Health Organization 1987. WHO Expert
Committee on Onchocerciasis. Geneva, $167 \mathrm{pp}$. Yen C 1938. Studies on Dirofilaria immitis Leidy, with special reference to the susceptibility of some Minnesota species of mosquitoes to the infection. $J$ Parasitol 3: 189-205. 